\title{
Biosynthetic Pathway Investigations and Gene Cluster of Curacin A, an Antitubulin Natural Product from the Tropical Marine Cyanobacterium Lyngbya majuscula
}

Zunxue Chang, Namthip Sitachitta, James Rossi, Mary Ann Roberts, Patricia M. Flatt, David Sherman, William H. Gerwick

\section{Supporting Information}

S1. The ${ }^{13} \mathrm{C}$ NMR spectrum of curacin A (1) produced during supplementation of Lyngbya majuscula cultures with sodium $\left[1-{ }^{13} \mathrm{C},{ }^{18} \mathrm{O}_{2}\right]$ acetate, showing an additional upfield shifted peak for C-13 for the incorporation of the double label at this position.

S2. The ${ }^{13} \mathrm{C}$ NMR spectrum of curacin A (1) produced during supplementation of Lyngbya majuscula cultures with sodium $\left[2-{ }^{13} \mathrm{C}\right]$ acetate. The inset shows the $12 \mathrm{~Hz}{ }^{1} J_{\mathrm{CC}}$ coupling between C-19 and C-20 which results from incorporation of this labeled precursor.

S3. Comparison of two selected regions of the ${ }^{13} \mathrm{C}$ NMR spectra of curacin A (1) with a natural abundance of ${ }^{13} \mathrm{C}$ (A and $\mathrm{C}$ ) versus curacin A produced during supplementation with $\left[2-{ }^{13} \mathrm{C},{ }^{15} \mathrm{~N}\right]$ glycine showing couplings from $\left[2-{ }^{13} \mathrm{C},{ }^{15} \mathrm{~N}\right]$ glycine. 
S1. . The ${ }^{13} \mathrm{C}$ NMR spectrum of curacin A (1) produced during supplementation of Lyngbya majuscula cultures with sodium $\left[1-{ }^{13} \mathrm{C},{ }^{18} \mathrm{O}_{2}\right]$ acetate, showing an additional upfield shifted peak for C-13 for the incorporation of the double label at this position.

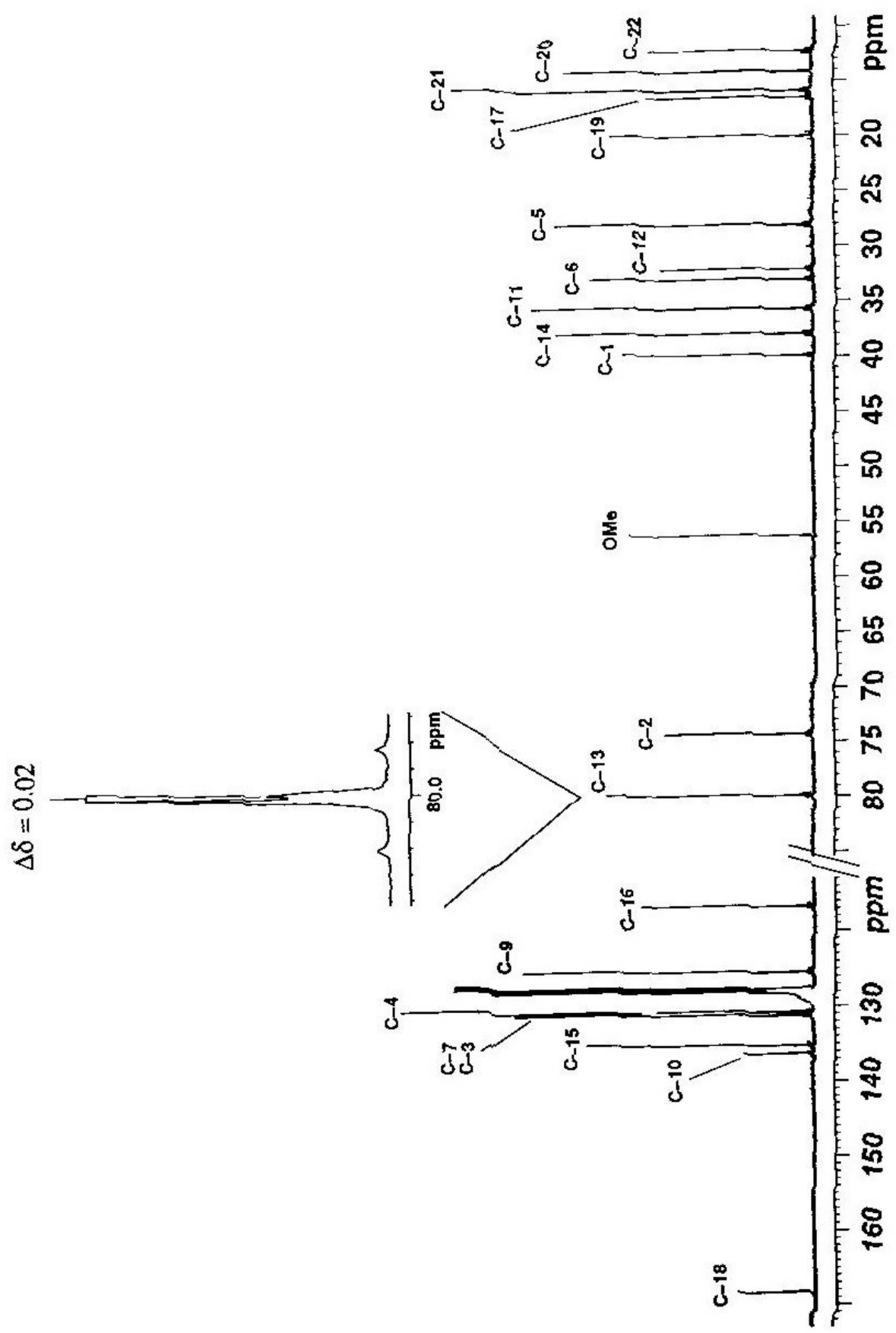


S2. The ${ }^{13} \mathrm{C}$ NMR spectrum of curacin A (1) produced during supplementation of Lyngbya majuscula cultures with sodium $\left[2-{ }^{13} \mathrm{C}\right]$ acetate. The inset shows the $12 \mathrm{~Hz}{ }^{1} J_{\mathrm{CC}}$ coupling between C-19 and C-20 which results from incorporation of this labeled precursor.

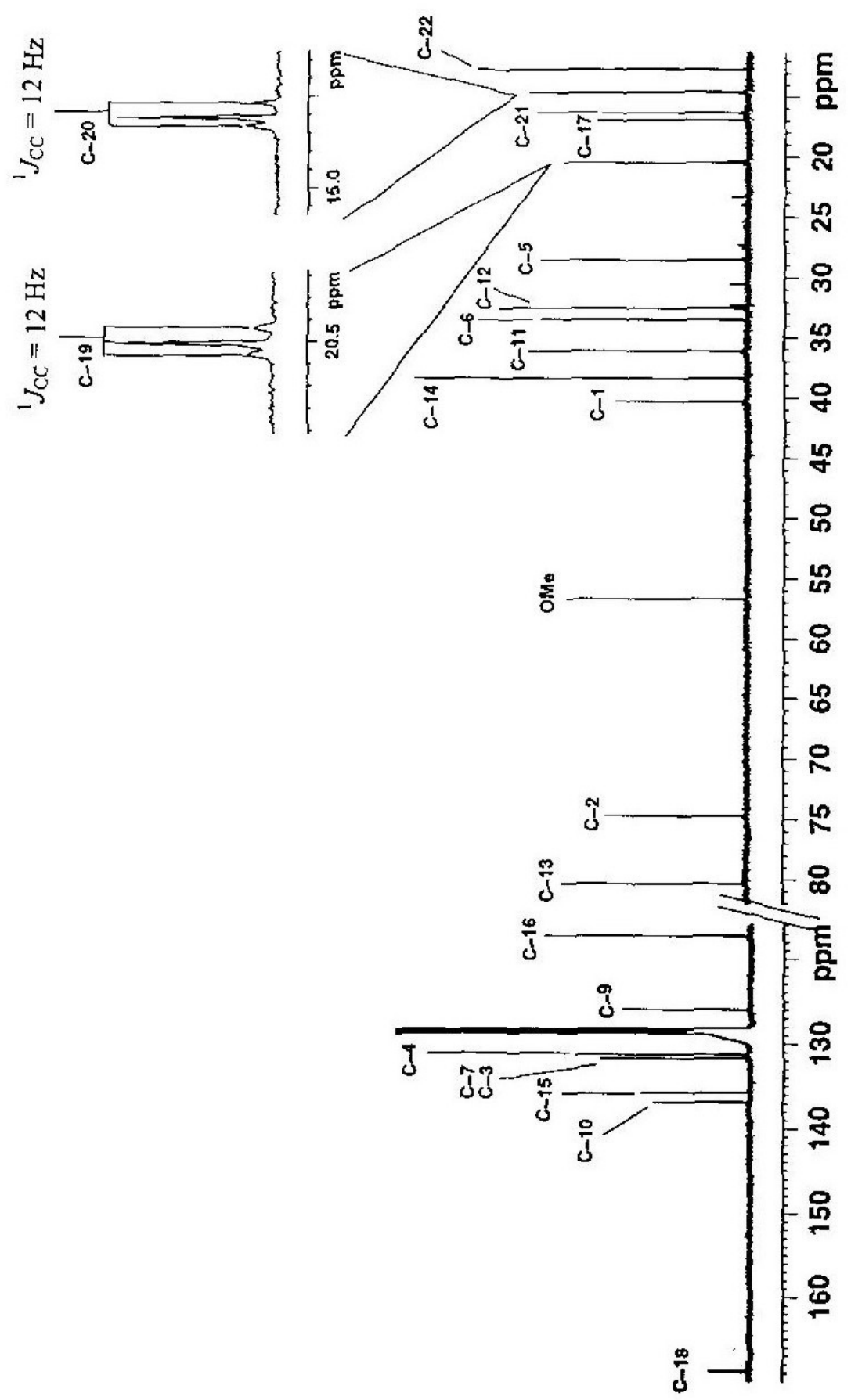


S3. Comparison of two selected regions of the ${ }^{13} \mathrm{C}$ NMR spectra of curacin $\mathrm{A}(\mathbf{1})$ with a natural abundance of ${ }^{13} \mathrm{C}(\mathrm{A}$ and $\mathrm{C})$ versus curacin A produced during supplementation with $\left[2-{ }^{13} \mathrm{C},{ }^{15} \mathrm{~N}\right]$ glycine showing couplings from $\left[2-{ }^{13} \mathrm{C},{ }^{15} \mathrm{~N}\right] \mathrm{glycine}$.

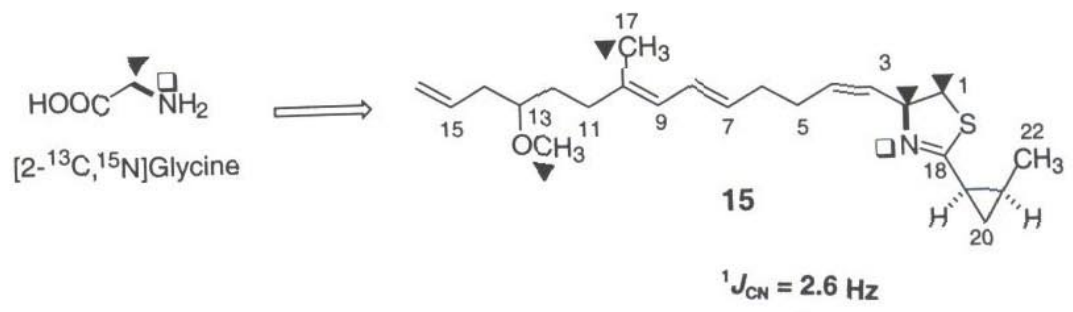

A.

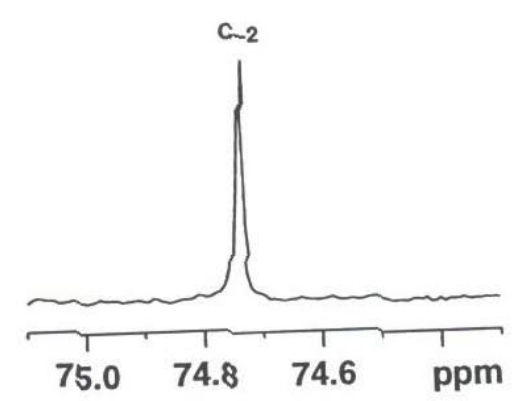

C.

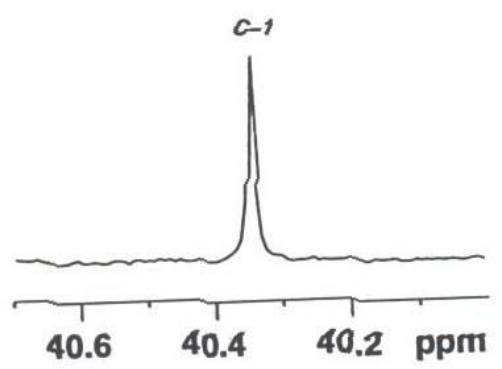

B.
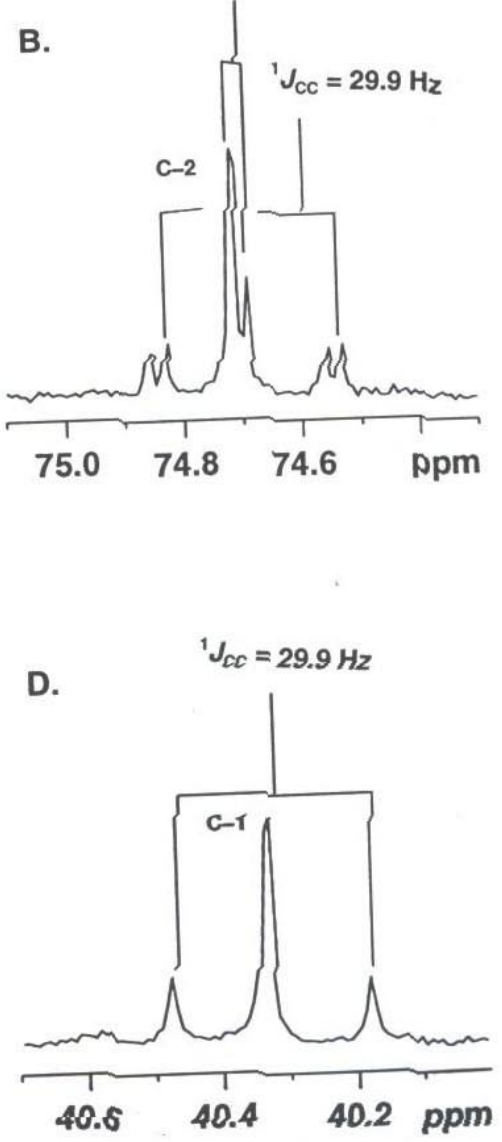